\title{
MALDI-TOF MS Analysis of Condensed Tannins with Potent Antioxidant Activity from the Leaf, Stem Bark and Root Bark of Acacia confusa
}

\author{
Shu-Dong Wei, Hai-Chao Zhou, Yi-Ming Lin *, Meng-Meng Liao and Wei-Ming Chai \\ Key Laboratory of the Ministry of Education for Coastal and Wetland Ecosystems, School of Life \\ Sciences, Xiamen University, Xiamen 361005, China \\ * Author to whom correspondence should be addressed; E-Mail: linym@xmu.edu.cn; \\ Tel.: +86-592-2187657.
}

Received: 26 May 2010; in revised form: 10 June 2010 / Accepted: 12 June 2010 /

Published: 15 June 2010

\begin{abstract}
The structures of the condensed tannins from leaf, stem bark and root bark of Acacia confusa were characterized by matrix-assisted laser desorption/ionization time-offlight mass spectrometry (MALDI-TOF MS) analysis, and their antioxidant activities were measured using 1,1-diphenyl-2-picrylhydrazyl (DPPH) free radical scavenging and ferric reducing/antioxidant power (FRAP) assays. The results showed that the condensed tannins from stem bark and root bark include propelargonidin and procyanidin, and the leaf condensed tannins include propelargonidin, procyanidin and prodelphinidin, all with the procyanidin dominating. The condensed tannins had different polymer chain lengths, varying from trimers to undecamers for leaf and root bark and to dodecamers for stem bark. The condensed tannins extracted from the leaf, stem bark and root bark all showed a very good DPPH radical scavenging activity and ferric reducing power.
\end{abstract}

Keywords: Acacia confusa; condensed tannins; MALDI-TOF MS; antioxidant activity

\section{Introduction}

Tannins are polyphenols that occur in plants, where they can amount to $20 \%$ of the plant dry weight, depending on the plant and organ [1-3]. Two types of tannins occur in vascular plants: the condensed and the hydrolysable [4]. Condensed tannins are formed of flavan-3-ol units, which are linked together 
through $\mathrm{C} 4-\mathrm{C} 6$ or $\mathrm{C} 4-\mathrm{C} 8$ bonds to oligomers and high molecular weight polymers [5-8]. The diversity of condensed tannins is given by the structural variability of the monomer units: different hydroxylation patterns of the aromatic rings $\mathrm{A}$ and $\mathrm{B}$, different stereochemistry at the chiral centers $\mathrm{C} 2$ and $\mathrm{C} 3$, and the distinct location and stereochemistry of the interflavanoid bond (Figure 1).

Figure 1. Chemical structure of flavan-3-ol monomer units and condensed tannins.
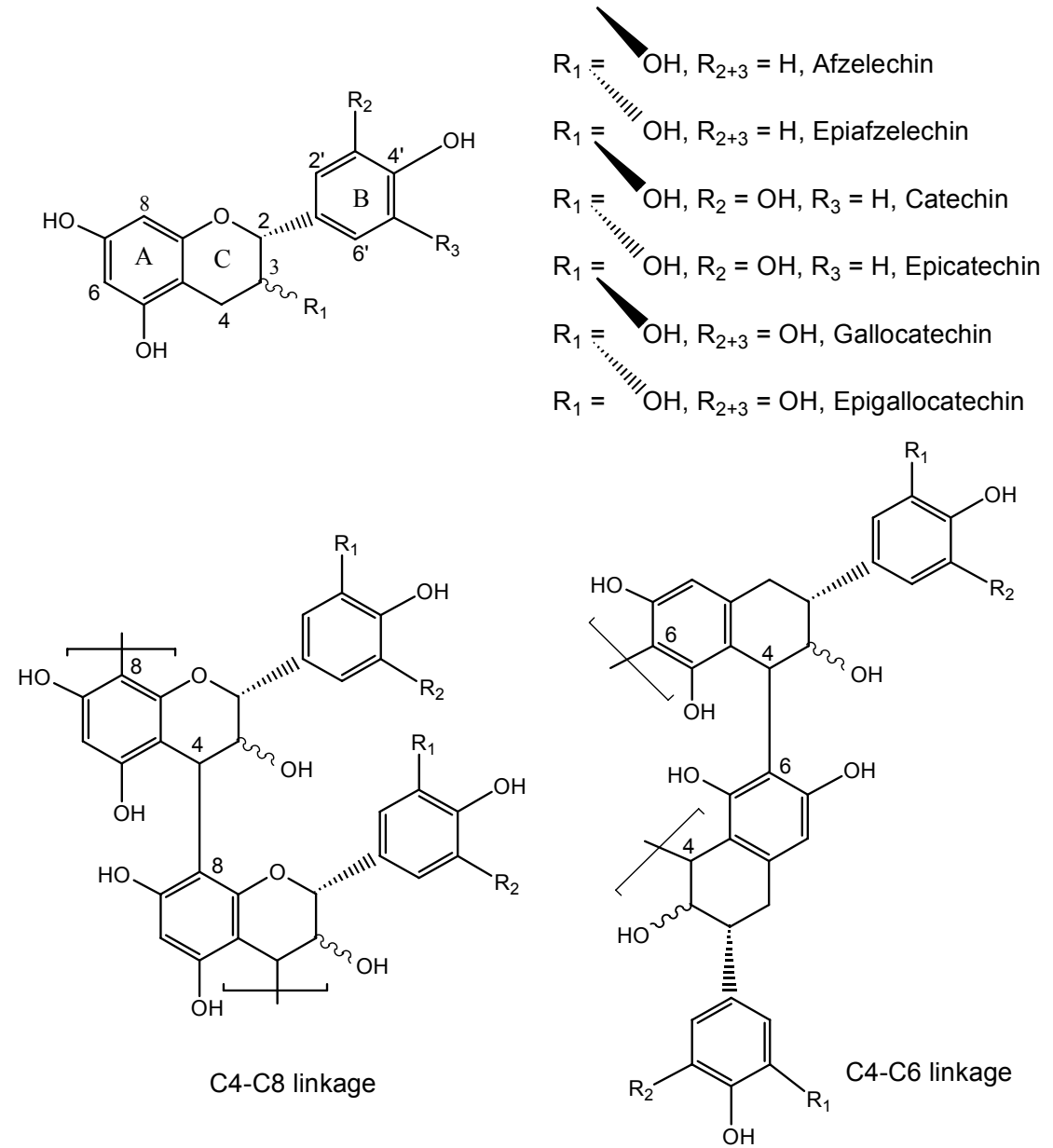

$$
\begin{aligned}
& \mathrm{R}_{1+2}=\mathrm{H}, \text { Propelargonidin } \\
& \mathrm{R}_{1}=\mathrm{OH}, \mathrm{R}_{2}=\mathrm{H}, \text { Procyanidin } \\
& \mathrm{R}_{1+2}=\mathrm{OH}, \text { Prodelphinidin }
\end{aligned}
$$

Condensed tannins are considered as functional ingredients in botanical, nutritional supplements and therefore they are attracting more attention. However, the bioactivity capacity of plant condensed tannins is generally recognized to be largely dependent on their structure and particularly the degree of polymerization $[9,10]$. The structural elucidation of these compounds, especially the higher polymers, is difficult because of their heterogeneous character. Due to the complexity and diversity, the characterization of highly polymerized condensed tannins thus remains very challenging, and less is known regarding structure-activity relationships [11,12]. Various techniques including NMR, acidcatalyzed depolymerization of the polymers in the presence of nucleophilic reagents, and MALDI-TOF MS have been used to characterize condensed tannins [13-19]. 
Acacia confusa is traditionally used as a medicinal plant [20]. An aqueous extract of $A$. confusa leaves was used in Taiwan for wound healing and anti-blood-stasis [21]. The crude extracts of heartwood, leaf, and bark contain a wide variety of phenolic compounds [20,22-26] and some also show an excellent antioxidant activity [22,25]. Therefore, this plant might be a good candidate for further development as a nutraceutical or an antioxidant remedy. Previous studies showed that the structures of the main monomers constituting the condensed tannins from leaves, twigs, and branches of A. confusa were catechin and epicatechin [27,28]. However, detailed information on the condensed tannins' profiles, including polymer chain length, chemical constitution of individual chains, and the sequential succession of monomer units in individual chains, has not been reported. In this study, contents of total phenolics and extractable condensed tannins of leaf, stem bark and root bark of $A$. confusa were determined, and the structures of condensed tannins from them were characterized by MALDI-TOF MS. In addition, the free radical scavenging capacities and ferric reducing power of condensed tannins from leaf, stem bark and root bark are also discussed.

\section{Results and Discussion}

\subsection{Content of total phenolics and extractable condensed tannins}

Root bark had the highest contents of total phenolics and extractable condensed tannins, followed by stem bark and leaf (Table 1). Plant phenolics constitute one of the major groups of compounds acting as primary antioxidants or free radical terminators [29]. Phenolic compounds are considered to be the major contributor to the antioxidant activity of vegetables, fruits or medicinal plants. The antioxidant activities of phenolic compounds are attributed to their redox properties, which allow them to act as reducing agents, hydrogen donators, singlet oxygen quenchers, etc. [22,30]. Our results revealed that $A$. confusa (especially root bark and stem bark) had high levels of phenolics, and might be potential sources of natural antioxidants.

Table 1. Contents of total phenolics and extractable condensed tannins in leaf, stem bark and root bark of $A$. confusa.

\begin{tabular}{ccc}
\hline Samples & $\begin{array}{c}\text { Total phenolics } \\
(\mathbf{m g} / \mathbf{g})\end{array}$ & $\begin{array}{c}\text { Extractable condensed } \\
\text { tannins } \mathbf{( m g} / \mathbf{g})\end{array}$ \\
\hline Leaf & $180.08 \pm 2.67 \mathrm{c}$ & $64.17 \pm 1.44 \mathrm{c}$ \\
Stem bark & $394.69 \pm 5.03 \mathrm{~b}$ & $247.76 \pm 10.93 \mathrm{~b}$ \\
Root bark & $467.99 \pm 6.22 \mathrm{a}$ & $280.70 \pm 11.75 \mathrm{a}$ \\
\hline
\end{tabular}

Using respective purified tannins from leaf, stem bark and root bark as the standards. Different letters in the same column show significant differences from each other at $\mathrm{P}<0.05$ level.

\subsection{MALDI-TOF MS analysis}

MALDI-TOF MS is very sensitive to molecular weight, and nowadays is considered a method of choice for analysis of tannins exhibiting large structural heterogeneity. With this technique fragmentation of the analyte molecules upon laser irradiation can be substantially reduced by embedding them in a light absorbing matrix. As a result, intact analyte molecules are desorbed and ionized along with the matrix, and they can be analyzed in a mass spectrometer [31,32]. MALDI-TOF 
MS produces only a singly charged molecular ion for each parent molecule and allows detection of high mass with precision [33]. Several factors including the selection of an appropriate matrix, optimal mixing and optimal selection of cationization reagent must be optimized to develop MALDI-TOF MS techniques. When $\mathrm{Cs}^{+}$was employed as the cationization reagent for MALDI, Chinese gallotannins gave a relatively simple MALDI-TOF spectrum [34].

Figure 2 shows the MALDI-TOF mass spectra of the polymeric tannin mixtures of the different parts of $A$. confusa, recorded as $\mathrm{Cs}^{+}$adducts in the positive ion reflectron mode. The polymeric character is reflected by the periodic peak series representing different polymers. Condensed tannins isolated from the leaf, stem bark and root bark are characterized by mass spectra with a series of peaks with distances of $288 \mathrm{Da}$, corresponding to one catechin/epicatechin monomer, therefore, prolongation of condensed tannins is due to the addition of catechin/epicatechin monomers (Table 2).

Figure 2. MALDI-TOF positive reflectron mode mass spectra of the condensed tannins from different parts of $A$. confusa: (a) leaf, (b) stem bark, (c) root bark.

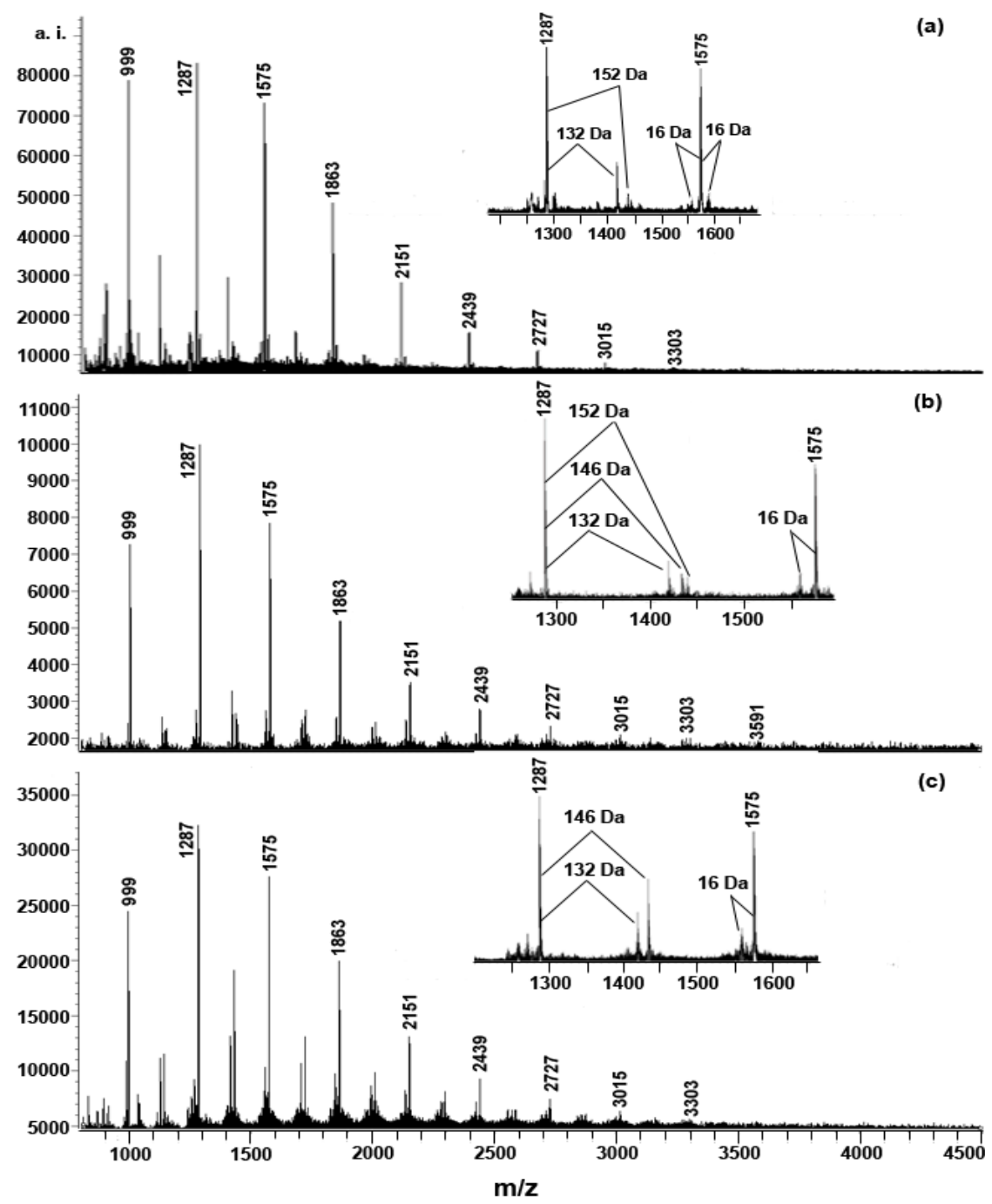


Table 2. MALDI-TOF MS of condensed tannins from different parts of $A$. confusa.

\begin{tabular}{|c|c|c|c|c|c|c|c|c|c|}
\hline \multirow[b]{2}{*}{ Polymer } & \multirow[b]{2}{*}{$\mathbf{n}_{1}$} & \multirow[b]{2}{*}{$\mathbf{n}_{2}$} & \multirow[b]{2}{*}{$\mathbf{n}_{3}$} & \multirow[b]{2}{*}{$\mathbf{n}_{4}$} & \multirow[b]{2}{*}{$\mathbf{n}_{5}$} & \multirow{2}{*}{$\begin{array}{l}\text { Calculated } \\
{[\mathrm{M}+\mathrm{Cs}]^{+}}\end{array}$} & \multicolumn{3}{|c|}{ Observed [M + Cs] $]^{+}$} \\
\hline & & & & & & & Leaf & $\begin{array}{l}\text { Stem } \\
\text { bark }\end{array}$ & $\begin{array}{l}\text { Root } \\
\text { bark }\end{array}$ \\
\hline \multirow[t]{5}{*}{ Trimer } & 0 & 3 & 0 & 0 & 0 & 999 & 999 & 999 & 999 \\
\hline & 1 & 2 & 0 & 0 & 0 & 983 & 983 & 983 & 983 \\
\hline & 0 & 2 & 1 & 0 & 0 & 1015 & 1015 & -- & -- \\
\hline & 0 & 3 & 0 & 1 & 0 & 1145 & -- & 1145 & 1145 \\
\hline & 0 & 3 & 0 & 0 & 1 & 1151 & 1151 & 1151 & -- \\
\hline \multirow[t]{5}{*}{ Tetramer } & 0 & 4 & 0 & 0 & 0 & 1287 & 1287 & 1287 & 1287 \\
\hline & 1 & 3 & 0 & 0 & 0 & 1271 & 1271 & 1271 & 1271 \\
\hline & 0 & 3 & 1 & 0 & 0 & 1303 & 1303 & -- & -- \\
\hline & 0 & 4 & 0 & 1 & 0 & 1433 & -- & 1433 & 1433 \\
\hline & 0 & 4 & 0 & 0 & 1 & 1439 & 1439 & 1439 & -- \\
\hline \multirow[t]{5}{*}{ Pentamer } & 0 & 5 & 0 & 0 & 0 & 1575 & 1575 & 1575 & 1575 \\
\hline & 1 & 4 & 0 & 0 & 0 & 1559 & 1559 & 1559 & 1559 \\
\hline & 0 & 4 & 1 & 0 & 0 & 1591 & 1591 & -- & -- \\
\hline & 0 & 5 & 0 & 1 & 0 & 1721 & -- & 1721 & 1721 \\
\hline & 0 & 5 & 0 & 0 & 1 & 1727 & 1727 & 1727 & -- \\
\hline \multirow[t]{5}{*}{ Hexamer } & 0 & 6 & 0 & 0 & 0 & 1863 & 1863 & 1863 & 1863 \\
\hline & 1 & 5 & 0 & 0 & 0 & 1847 & 1847 & 1847 & 1847 \\
\hline & 0 & 5 & 1 & 0 & 0 & 1879 & 1879 & -- & -- \\
\hline & 0 & 6 & 0 & 1 & 0 & 2009 & -- & 2009 & 2009 \\
\hline & 0 & 6 & 0 & 0 & 1 & 2015 & 2015 & 2015 & -- \\
\hline \multirow[t]{5}{*}{ Heptamer } & 0 & 7 & 0 & 0 & 0 & 2151 & 2151 & 2151 & 2151 \\
\hline & 1 & 6 & 0 & 0 & 0 & 2135 & 2135 & 2135 & 2135 \\
\hline & 0 & 6 & 1 & 0 & 0 & 2167 & 2167 & -- & -- \\
\hline & 0 & 7 & 0 & 1 & 0 & 2297 & -- & 2297 & 2297 \\
\hline & 0 & 7 & 0 & 0 & 1 & 2303 & 2303 & 2303 & -- \\
\hline \multirow[t]{5}{*}{ Octamer } & 0 & 8 & 0 & 0 & 0 & 2439 & 2439 & 2439 & 2439 \\
\hline & 1 & 7 & 0 & 0 & 0 & 2423 & 2423 & 2423 & 2423 \\
\hline & 0 & 7 & 1 & 0 & 0 & 2455 & 2455 & -- & -- \\
\hline & 0 & 8 & 0 & 1 & 0 & 2585 & -- & 2585 & 2586 \\
\hline & 0 & 8 & 0 & 0 & 1 & 2591 & 2591 & 2591 & -- \\
\hline \multirow[t]{3}{*}{ Nonamer } & 0 & 9 & 0 & 0 & 0 & 2727 & 2727 & 2727 & 2727 \\
\hline & 1 & 8 & 0 & 0 & 0 & 2711 & -- & 2711 & 2711 \\
\hline & 0 & 9 & 0 & 0 & 1 & 2873 & -- & 2873 & -- \\
\hline \multirow[t]{2}{*}{ Decamer } & 0 & 10 & 0 & 0 & 0 & 3015 & 3015 & 3015 & 3015 \\
\hline & 0 & 10 & 0 & 1 & 0 & 3161 & -- & 3161 & 3161 \\
\hline Undecamer & 0 & 11 & 0 & 0 & 0 & 3303 & 3303 & 3303 & 3303 \\
\hline Dodecamer & 0 & 12 & 0 & 0 & 0 & 3591 & -- & 3591 & -- \\
\hline
\end{tabular}

$\mathrm{n}_{1:}$ Number of afzelechin/epiafzelechin units; $\mathrm{n}_{2}$ : Number of catechin/epicatechin units; $\mathrm{n}_{3}$ : Number of gallocatechin/epigallocatechin units; $\mathrm{n}_{4}$ : Number of rhamnoside; $\mathrm{n}_{5}$ : Number of galloyl units; "--" means no observed peaks corresponding to the calculated ones. 
The condensed tannins from the three different parts of A. confusa had different polymer chain length varying from trimers to undecamers for leaf and root bark and to dodecamers for stem bark. The spectra did not contain ions with 2 Da lower than that of the highest peaks among the polyflavan-3-ols polymers. In addition to the predicted homopolyflavan-3-ol mass series mentioned above, each DP had a subset of masses 16 Da lower in the spectra of stem bark and root bark (Figure 2 and Table 2). These masses indicated the polymer chains containing monomers with only one hydroxyl group (16 $\mathrm{Da}$ ) on the aromatic ring B. In contrast, the mass spectrum of leaf condensed tannins is more complicated. Each DP had a subset of masses 16 Da lower, and the subset of masses 16 Da higher were also detected, which can be explained by heteropolymers of repeating flavan-3-ol units containing an additional hydroxyl group at the position 5 ' of the B-ring. Given the absolute masses corresponding to each peak, it was further suggested that the condensed tannins from stem bark and root bark contain propelargonidin and procyanidin, and the leaf condensed tannins contain propelargonidin, procyanidin and prodelphinidin, all with the procyanidin dominating.

Each peak of the condensed tannins was also followed by mass signals at a distance of $152 \mathrm{Da}$ (corresponding to the addition of one galloyl group at the heterocyclic C-ring) in spectra of leaf and stem bark, $146 \mathrm{Da}$ (corresponding to the addition of one rhamnoside group at the heterocyclic C-ring) in spectra of stem bark and root bark, and $132 \mathrm{Da}$ (corresponding to the addition of one arabinoside group at the heterocyclic $\mathrm{C}$-ring or additional one $\mathrm{CS}^{+}$) in spectra of leaf, stem bark and root bark. No series of compounds that are 2 Da multiples lower than those described peaks for heteropolyflavan-3ols were detected, so A-type interflavan ether linkage does not occur between adjacent flavan-3-ol subunits for leaf, stem bark and root bark. All compounds are linked by B-type bonds. Structures of condensed tannins from different parts of $A$. confusa were thus successfully characterized using MALDI-TOF MS for the first time.

\subsection{DPPH radical scavenging activity}

The 1,1-diphenyl-2-picrylhydrazyl (DPPH) radical is usually used as a reagent to evaluate the free radical scavenging activity of antioxidants [35]. DPPH is a stable free radical and accepts an electron or hydrogen radical to become a stable diamagnetic molecule [36].

Figure 3. Remaining DPPH after addition of the condensed tannins from different parts of A. confusa for $30 \mathrm{~min}$.

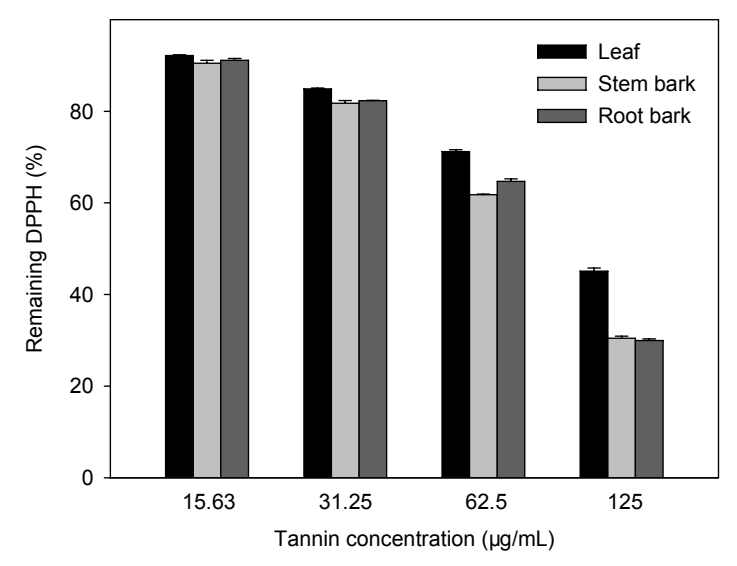


The reduction capability of DPPH radical is determined by the decrease in absorbance at $517 \mathrm{~nm}$ induced by antioxidants [37]. The percentages of DPPH remaining in the presence of condensed tannins from different parts of A. confusa at different concentrations are shown in Figure 3. A doseresponse relationship is found in the radical scavenging activity; the activity increased with the increasing concentration of condensed tannins. The quality of the antioxidants about the condensed tannins from different parts of $A$. confusa was determined by the $\mathrm{IC}_{50}$ values (the concentration with scavenging activity of $50 \%$ ). A lower value of $\mathrm{IC}_{50}$ indicates greater antioxidant activity.

The $\mathrm{IC}_{50}$ values of the stem bark $(87.85 \pm 0.52 \mu \mathrm{g} / \mathrm{mL})$ and root bark $(89.03 \pm 0.50 \mu \mathrm{g} / \mathrm{mL})$ were significantly lower than those of leaf and other two standards (ascorbic acid and BHA), indicating the condensed tannins of stem bark and root bark exhibited the higher radical scavenging effect than them. The scavenging effect on the DPPH radical decreased in the order: stem bark $\approx$ root bark $>$ leaf $>$ ascorbic acid $>$ BHA.

Table 3. Antioxidant activities of the condensed tannins from different parts of $A$. confusa using the (DPPH) free radical scavenging assay and the (FRAP) ferric reducing antioxidant assay.

\begin{tabular}{ccc}
\hline \multirow{2}{*}{ Samples } & \multicolumn{2}{c}{ Antioxidant activity } \\
\cline { 2 - 3 } & IC $_{\mathbf{5 0 / D P P H}}(\boldsymbol{\mu g} / \mathbf{m L})^{\boldsymbol{a}}$ & FRAP (mmol AAE/g) $^{\boldsymbol{b}}$ \\
\hline Leaf & $113.06 \pm 1.52 \mathrm{c}$ & $5.92 \pm 0.04 \mathrm{a}$ \\
Stem bark & $87.85 \pm 0.52 \mathrm{~d}$ & $5.89 \pm 0.14 \mathrm{a}$ \\
Root bark & $89.03 \pm 0.50 \mathrm{~d}$ & $5.69 \pm 0.09 \mathrm{a}$ \\
Ascorbic acid & $118.88 \pm 3.33 \mathrm{~b}$ & -- \\
BHA & $126.21 \pm 1.32 \mathrm{a}$ & $4.93 \pm 0.09 \mathrm{~b}$ \\
\hline
\end{tabular}

${ }^{a}$ The antioxidant activity was evaluated as the content of the test sample required to decrease the absorbance at $517 \mathrm{~nm}$ by $50 \%$ in comparison to the control; ${ }^{b}$ FRAP values are expressed in mmol ascorbic acid equivalent/g sample in dry weight; BHA: Butylated hydroxyanisole. Values are expressed as mean of duplicate determinations \pm standard deviation; Different letters in the same column show significant differences from each other at $P<0.05$ level.

\subsection{Ferric reducing antioxidant power (FRAP)}

The FRAP assay is based on the redox reaction of ferric ion in the presence of a reducer. The reduction capacity of a compound may serve as a significant indicator of its potential antioxidant activity [38]. A higher absorbance corresponds to a higher ferric reducing power. All tannins showed increased ferric reducing power with the increasing concentration (Figure 4). At $125 \mu \mathrm{g} / \mathrm{mL}$, the reducing power of leaf $\left(A_{593}=0.94 \pm 0.01\right)$ was superior to stem bark $\left(A_{593}=0.90 \pm 0.02\right)$. The FRAP value, used to determine the antioxidant ability of different parts of $A$. confusa in present study, was expressed in ascorbic acid equivalents. The FRAP values for leaf, stem bark and root bark ranged from $5.69 \pm 0.09$ to $5.92 \pm 0.04 \mathrm{mmol} \mathrm{AAE} / \mathrm{g}$ dried tannins, and were all significantly higher than that of BHA (4.93 $\pm 0.09 \mathrm{mmol} \mathrm{AAE} / \mathrm{g}$ dried sample). 
Figure 4. Ferric reducing power after addition of the condensed tannins from different parts of A. confusa.

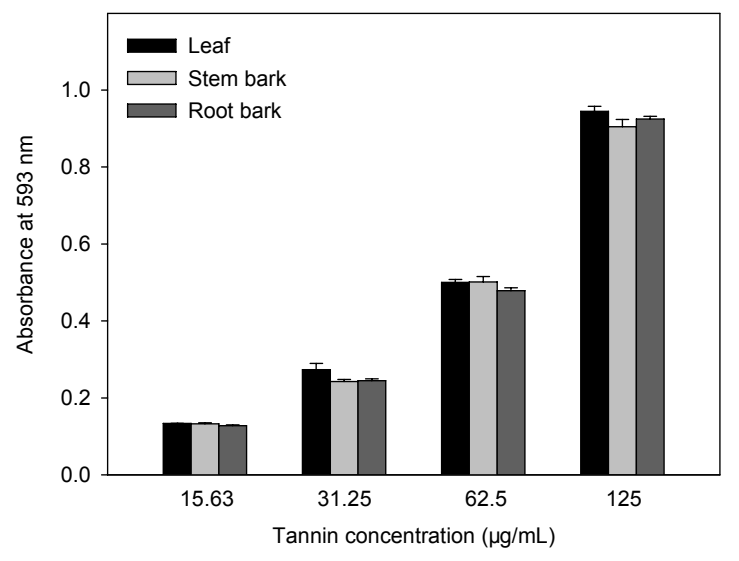

\section{Experimental}

\subsection{Chemicals and materials}

All solvents used were of analytical reagent (AR) purity grade. 1,1-Diphenyl-2-picrylhydrazyl (DPPH), 2,4,6-tripyridyl-S-triazine (TPTZ), ascorbic acid, butylated hydroxyanisole (BHA), and cesium chloride were purchased from Sigma-Aldrich (USA). Sephadex LH-20 was purchased from Amersham (USA). Leaf, stem bark and root bark of A. confusa were collected from Xiamen Botanical Garden, Fujian Province, China.

\subsection{Extraction and purification of the condensed tannins}

Freeze-dried leaf, stem bark and root bark powders (35 g of each) were extracted thrice with 7:3 $(\mathrm{v} / \mathrm{v})$ acetone-water solution $(3 \times 250 \mathrm{~mL})$ at room temperature. Each extract was filtered and pooled, and the solvent was removed under reduced pressure by use a rotary evaporator at $38{ }^{\circ} \mathrm{C}$. The remaining aqueous fraction was extracted thrice with hexane $(3 \times 150 \mathrm{~mL})$ in order to remove chlorophyll and lipophilic compounds. The remaining crude tannin fraction was chromatographed on an LH-20 column (Pharmacia Biotech, Uppsala, Sweden) which was first eluted with methanol-water $(50: 50, \mathrm{v} / \mathrm{v})$ and then with acetone-water $(7: 3, \mathrm{v} / \mathrm{v})$. The last fraction of purified condensed tannins was freezed-dried and stored at $-20^{\circ} \mathrm{C}$ before analysis by MALDI-TOF mass spectrometry.

\subsection{Determination of total phenolics and extractable condensed tannins}

Established procedures [39] were used. Total phenolic content was determined by the Prussian blue method [40]. Extractable condensed tannin content was assayed by the butanol- $\mathrm{HCl}$ method [41]. All used respective purified condensed tannins as the standards.

\subsection{MALDI-TOF MS analysis}

The MALDI-TOF MS spectra were recorded on a Bruker Reflex III instrument (Germany). The irradiation source was a pulsed nitrogen laser with a wavelength of $337 \mathrm{~nm}$, and the duration of the 
laser pulse was $3 \mathrm{~ns}$. In the positive reflectron mode, an accelerating voltage of $20.0 \mathrm{kV}$ and a reflectron voltage of $23.0 \mathrm{kV}$ were used. 2,5-Dihydroxybenzoic acid (DHB, $10 \mathrm{mg} / \mathrm{mL} \mathrm{30 \%}$ acetone solution) was used as the matrix. The sample solutions $(10 \mathrm{mg} / \mathrm{mL} 30 \%$ acetone solution) were mixed with the matrix solution at a volumetric ratio of 1:3. The mixture $(1 \mu \mathrm{L})$ was spotted to the steel target. Amberlite IRP-64 cation-exchange resin (Sigma-Aldrich, USA), equilibrated in deionized water, was used to deionize the analyte-matrix solution thrice. Cesium chloride $(1.52 \mathrm{mg} / \mathrm{mL})$ was mixed with the analyte-matrix solution $(1: 3, \mathrm{v} / \mathrm{v})$ to promote the formation of a single type of ion adduct $\left([\mathrm{M}+\mathrm{Cs}]^{+}\right)[42]$.

\subsection{DPPH radical scavenging activity}

The effect of purified condensed tannins on DPPH radical was determined according to the method of Braca et al. [43]. Aliquots $(0.1 \mathrm{~mL})$ of various concentrations of each freeze-dried sample at different concentrations $(15.63-125 \mu \mathrm{g} / \mathrm{mL}$ ) was added to DPPH solution ( $3 \mathrm{~mL}, 0.1 \mathrm{mM}$ in methanol solution). An equal amount of methanol and DPPH served as control. After the mixture was shaken and left temperature for $30 \mathrm{~min}$, the absorbance at $517 \mathrm{~nm}$ was measured. Lower absorbance of the reaction mixture indicates higher free radical scavenging activity. The $\mathrm{IC}_{50}$ value, defined as the amount of antioxidant necessary to decrease the initial DPPH concentration by $50 \%$, was calculated from the results and used for comparison. The capability to scavenge the DPPH radical was calculated by using the following equation:

\section{DPPH scavenging effect $(\%)=\left[\left(\mathrm{A}_{1}-\mathrm{A}_{2}\right) / \mathrm{A}_{1}\right] \times 100$}

where $A_{1}=$ the absorbance of the control reaction; $A_{2}=$ the absorbance in the presence of the sample. BHA and ascorbic acid were used as standards.

\subsection{Ferric reducing/antioxidant power (FRAP) assay}

FRAP assay is a simple and reliable colorimetric method commonly used for measuring the total antioxidant capacity [44]. In brief, prepared freshly FRAP reagent $(3 \mathrm{~mL})$ was mixed with test sample $(0.1 \mathrm{~mL})$ or methanol (for the reagent blank, $0.1 \mathrm{~mL}$ ). The FRAP reagent was prepared from $300 \mathrm{mmol} / \mathrm{L}$ acetate buffer ( $\mathrm{pH} 3.6$ ), $20 \mathrm{mmol} / \mathrm{L}$ ferric chloride and $10 \mathrm{mmol} / \mathrm{L}$ TPTZ made up in $40 \mathrm{mmol} / \mathrm{L}$ hydrochloric acid. All the above three solutions were mixed together in the ratio of 25:2.5:2.5 (v/v/v). The absorbance of reaction mixture at $593 \mathrm{~nm}$ was measured spectrophotometrically after incubation at $25^{\circ} \mathrm{C}$ for $10 \mathrm{~min}$. The FRAP values, expressed in mmol ascorbic acid equivalents $(\mathrm{AAE}) / \mathrm{g}$ dried tannins, were derived from a standard curve.

\subsection{Statistical analysis}

All data were expressed as means \pm standard deviation of three independent determinations. Oneway analysis of variance (ANOVA) was used, and the differences were considered to be significant at $P<0.05$. All statistical analyses were performed with SPSS 13.0 for Windows. 


\section{Conclusions}

Structures of condensed tannins from leaf, stem bark and root bark of $A$. confusa were characterized by MALDI-TOF MS analysis that showed that the condensed tannins from stem bark and root bark contain propelargonidin and procyanidin, and the leaf condensed tannins contain propelargonidin, procyanidin and prodelphinidin, all with the procyanidin dominating. The condensed tannins had different polymer chain lengths, varying from trimers to undecamers for leaf and root bark and to dodecamers for stem bark. The condensed tannins extracted from the leaf, stem bark and root bark all showed very good DPPH radical scavenging activity and ferric reducing power, suggesting that these extracts may be considered as new sources of natural antioxidants for food and nutraceutical products.

\section{Acknowledgements}

This work was supported by Program for New Century Excellent Talents in University (NCET-070725), and by the Scientific Research Foundation for the Returned Overseas Chinese Scholars, State Education Ministry.

\section{References}

1. Kraus, T.E.C.; Dahlgren, R.A.; Zasoski, R.J. Tannins in nutrient dynamics of forest ecosystems a review. Plant Soil 2003, 256, 41-66.

2. Lin, Y.M.; Liu, X.W.; Zhang, H.; Fan, H.Q.; Lin, G.H. Nutrient conservation strategies of a mangrove species Rhizophora stylosa under nutrient limitation. Plant Soil 2010, 326, 469-479.

3. Yu, Z.; Dahlgren, R.A. Evaluation of methods for measuring polyphenols in conifer foliage. $J$. Chem. Ecol. 2000, 26, 2119-2140.

4. Hernes, P.J.; Benner, R.; Cowie, G.L.; GOni, M.A.; Bergamaschi, B.A.; Hedges, J.I. Tannin diagenesis in mangrove leaves from a tropical estuary: A novel molecular approach. Geochim. Cosmochim. Acta 2001, 65, 3109-3122.

5. Hemingway, R.W.; Karchesy, J.J. Chemistry and Significance of Condensed Tannins; Plenum: New York, NY, USA, 1989.

6. Porter, L.J. The Flavanoids: Advances in Research Since 1980; Harborne, J.B., Ed.; Chapman and Hall: New York, NY, USA, 1988; pp. 21-62.

7. Porter, L.J. The Flavanoids: Advances in Research Since 1986; Harborne, J.B., Ed.; Chapman and Hall: London, UK, 1994; pp. 23-54.

8. Waterman, P.G.; Mole, S. Analysis of Phenolic Plant Metabolites; Blackwell Scientific Publications: Oxford, UK, 1994.

9. Svedström, U.; Vuorela, H.; Kostiainen, R.; Huovinen, K.; Laakso, I.; Hiltunen, R. Highperformance liquid chromatographic determination of oligomeric procyanidins from dimers up to the hexamer in hawthorn. J. Chromatogr. A 2002, 968, 53-60.

10. Noferi, M.; Masson, E.; Merlin, A.; Pizzi, A.; Deglise, X. Antioxidant characteristics of hydrolysable and polyflavonoid tannins: An ESR kinetics study. J. Appl. Polymer Sci. 1997, 63, 475-482. 
11. Hümmer, W.; Schreier, P. Analysis of proanthocyanidins. Mol. Nutr. Food Res. 2008, 52, 1381-1398.

12. Es-Safi, N.E.; Guyot, S.; Ducrot, P.H. NMR, ESI/MS, and MALDI-TOF/MS Analysis of Pear Juice Polymeric Proanthocyanidins with Potent Free Radical Scavenging Activity. J. Agric. Food Chem. 2006, 54, 6969-6977.

13. Behrens, A.; Maie, N.; Knicker, H.; Kögel-Knabner, I. MALDI-TOF mass spectrometry and PSD fragmentation as means for the analysis of condensed tannins in plant leaves and needles. Phytochemistry 2003, 62, 1159-1170.

14. Chen, Y.; Hagerman, A.E. Characterization of Soluble Non-covalent Complexes between Bovine Serum Albumin and [beta]-1, 2, 3, 4, 6-Penta-O-galloyl-d-glucopyranose by MALDI-TOF MS. $J$. Agric. Food Chem. 2004, 52, 4008-4011.

15. Rahim, A.A.; Rocca, E.; Steinmetz, J.; Jain Kassim, M.; Sani Ibrahim, M.; Osman, H. Antioxidant activities of mangrove Rhizophora apiculata bark extracts. Food Chem. 2008, 107, 200-207.

16. Vivas, N.; Nonier, M.F.; de Gaulejac, N.V.; Absalon, C.; Bertrand, A.; Mirabel, M. Differentiation of proanthocyanidin tannins from seeds, skins and stems of grapes (Vitis vinifera) and heartwood of Quebracho (Schinopsis balansae) by matrix-assisted laser desorption/ionization time-of-flight mass spectrometry and thioacidolysis/liquid chromatography/electrospray ionization mass spectrometry. Anal. Chim. Acta 2004, 513, 247-256.

17. Zhang, L.L.; Lin, Y.M. HPLC, NMR and MALDI-TOF MS analysis of condensed tannins from Lithocarpus glaber leaves with potent free radical scavenging activity. Molecules 2008, 13, 2986-2997.

18. Zhang, L.L.; Lin, Y.M.; Zhou, H.C.; Wei, S.D.; Chen, J.H. Condensed Tannins from Mangrove Species Kandelia candel and Rhizophora mangle and Their Antioxidant Activity. Molecules 2010, 15, 420-431.

19. Pasch, H.; Pizzi, A.; Rode, K. MALDI-TOF mass spectrometry of polyflavonoid tannins. Polymer 2001, 42, 7531-7539.

20. Wu, J.H.; Tung, Y.T.; Wang, S.Y.; Shyur, L.F.; Kuo, Y.H.; Chang, S.T. Phenolic antioxidants from the heartwood of Acacia confusa. J. Agric. Food Chem. 2005, 53, 5917-5921.

21. Kan, W.S., Leguminosae. In: Manual of Medicinal Plants in Taiwan; Kan, W.S., Ed.; National Research Institute of Chinese Medicine: Taipei, Taiwan, 1978; Volume 2, pp. 239-240.

22. Chang, S.T.; Wu, J.H.; Wang, S.Y.; Kang, P.L.; Yang, N.S.; Shyur, L.F. Antioxidant activity of extracts from Acacia confusa bark and heartwood. J. Agric. Food Chem. 2001, 49, 3420-3424.

23. Lee, T.H.; Qiu, F.; Waller, G.R.; Chou, C.H. Three new flavonol galloylglycosides from leaves of Acacia confusa. J. Nat. Prod. 2000, 63, 710-712.

24. Lee, T.H.; Liu, D.Z.; Hsu, F.L.; Wu, W.C.; Hou, W.C. Structure-activity Relationships of Five Myricetin Galloylglycosides from Leaves of Acacia Confusa. Bot. Stud. 2006, 47, 37-43.

25. Tung, Y.T.; Wu, J.H.; Kuo, Y.H.; Chang, S.T. Antioxidant activities of natural phenolic compounds from Acacia confusa bark. Bioresour. Technol. 2007, 98, 1120-1123.

26. Tung, Y.T.; Wu, J.H.; Huang, C.Y.; Kuo, Y.H.; Chang, S.T. Antioxidant activities and phytochemical characteristics of extracts from Acacia confusa bark. Bioresour. Technol. 2009, $100,509-514$. 
27. Hsieh, C.Y.; Chang, S.T. Antioxidant Activities and Xanthine Oxidase Inhibitory Effects of Phenolic Phytochemicals from Acacia confusa Twigs and Branches. J. Agric. Food Chem. 2010, $58,1578-1583$.

28. Tung, Y.T.; Wu, J.H.; Hsieh, C.Y.; Chen, P.S.; Chang, S.T. Free radical-scavenging phytochemicals of hot water extracts of Acacia confusa leaves detected by an on-line screening method. Food Chem. 2009, 115, 1019-1024.

29. Cao, G.; Sofic, E.; Prior, R.L. Antioxidant and prooxidant behavior of flavonoids: Structureactivity relationships. Free Radic. Biol. Med. 1997, 22, 749-760.

30. Rice-Evans, C.A.; Miller, N.J.; Paganga, G. Structure-antioxidant activity relationships of flavonoids and phenolic acids. Free Radic. Biol. Med. 1996, 20, 933-956.

31. Jerez, M.; Sineiro, J.; Guitián, E.; Núñez, M.J. Identification of polymeric procyanidins from pine bark by mass spectrometry. Rap. Comm. Mass Spec. 2009, 23, 4013-4018.

32. Oo, C.W.; Pizzi, A.; Pasch, H.; Kassim, M.J. Study on the structure of mangrove polyflavonoid tannins with MALDI-TOF mass spectrometry. J. Appl. Polym. Sci. 2008, 109, 963-967.

33. Montaudo, G.; Montaudo, M.S.; Samperi, F. Martix-assisted laser desorption/ionization mass spectrometry of polymers (MALDI-MS). In Mass Spectrometry of Polymers; Montaudo, G., Lattimer, R.P., Eds.; CRC Press: Boca Raton, FL, 2002; pp. 419-521.

34. Xiang, P.; Lin, Y.; Lin, P.; Xiang, C.; Yang, Z.; Lu, Z. Effect of cationization reagents on the matrix-assisted laser desorption/ionization time-of-flight mass spectrum of Chinese gallotannins. $J$. Appl. Polym. Sci. 2007, 105, 859-864.

35. Oyaizu, M. Studies on products of browning reactions: Antioxidative activities of products of browning reaction prepared from glucosamine. Jpn. J. Nutr. 1986, 44, 307-315.

36. Soare, J.R.; Dinis, T.C.P.; Cunha, A.P.; Almeida, L. Antioxidant activities of some extracts of Thymus zygis. Free Radic. Res. 1997, 26, 469-478.

37. Kumaran, A.; Karunakaran, J. In vitro antioxidant activities of methanol extracts of five Phyllanthus species from India. Food. Sci. Technol. 2007, 40, 344-352.

38. Meir, S.; Kanner, J.; Akiri, B.; Philosoph-Hadas, S. Determination and involvement of aqueous reducing compounds in oxidative defense systems of various senescing leaves. J. Agric. Food Chem. 1995, 43, 1813-1819.

39. Lin, Y.M.; Liu, J.W.; Xiang, P.; Lin, P.; Ye, G.F.; Sternberg, L. daS. L. Tannin dynamics of propagules and leaves of Kandelia candel and Bruguiera gymnorrhiza in the Jiulong River Estuary, Fujian, China. Biogeochemistry 2006, 78, 343-359.

40. Graham, H.D. Stabilization of the Prussian blue color in the determination of polyphenols. $J$. Agric. Food Chem. 1992, 40, 801-805.

41. Terrill, T.H.; Rowan, A.M.; Douglas, G.B.; Barry, T.N. Determination of extractable and bound condensed tannin concentrations in forage plants, protein concentrate meals and cereal grains. $J$. Sci. Food Agric. 1992, 58, 321-329.

42. Xiang, P.; Lin, Y.M.; Lin, P.; Xiang, C. Effects of adduct ions on matrix-assisted laser desorption/ionization time of flight mass spectrometry of condensed tannins: A prerequisite knowledge. Chin. J. Anal. Chem. 2006, 34, 1019-1022.

43. Braca, A.; De Tommasi, N.; Di Bari, L.; Pizza, C.; Politi, M.; Morelli, I. Antioxidant principles from Bauhinia tarapotensis. J. Nat. Prod. 2001, 64, 892-895. 
44. Benzie, I.F.F.; Strain, J.J. The ferric reducing ability of plasma (FRAP) as a measure of "antioxidant power": The FRAP assay. Anal. Biochem. 1996, 239, 70-76.

Sample Availability: Samples of the compounds are available from the authors.

(C) 2010 by the authors; licensee MDPI, Basel, Switzerland. This article is an Open Access article distributed under the terms and conditions of the Creative Commons Attribution license (http://creativecommons.org/licenses/by/3.0/). 